\title{
O PATRIARCALISMO EM O CONTO DA AIA
}

\author{
PATRIARCHALISM IN THE HANDMAID'S TALE
}

\begin{abstract}
RESUMO
Temas abordados pela literatura podem ser visualizados na sociedade, sejam estes incorporados a um cenário real ou distópico, como é o caso da obra O Conto da Aia, de Margaret Atwood. Publicado pela primeira vez em 1985, esta obra aborda a vida das mulheres após um golpe de Estado que instaurou uma teonomia totalitária e fundamentalmente cristã em uma região dos Estados Unidos. Considerando isto, o presente artigo aborda a obra de Atwood sob uma reflexão sociológica acerca do patriarcalismo. Para tal, partimos dos estudos de autores como Simone de Beauvoir, Maria Luísa Ribeiro Ferreira, Flávia Biroli, Michelle Perrot, entre outros. Através da perspectiva de base sociológica, acreditamos ser possível um entendimento da manifestação do patriarcalismo em $O$ Conto da Aia e as implicações que tal sistema acarretou para a vida das personagens, o que viabiliza uma reflexão sobre uma sociedade pautada em socializações diferentes para homens e mulheres.
\end{abstract}

Palavras-chave: O Conto da Aia. Patriarcalismo. Margaret Atwood.

\begin{abstract}
Themes approached by literature can be visualized in society, whether incorporated into a real or dystopian setting, such as Margaret Atwood's The Handmaid's Tale. First published in 1985, this book addresses women's lives after a coup d'état that established a totalitarian and fundamentally Christian theonomy in a region of the United States. Takin this into account, this article approaches Atwood's work under a sociological reflection on patriarchalism. For such, studies by authors such as Simone de Beauvoir, Maria Luisa Ribeiro Ferreira, Flavia Biroli, Michelle Perrot, among others. From a sociological perspective, we believe it is possible to achieve an understanding of the manifestation of patriarchalism in The Handmaid's Tale and the implications that such a system had for the life of the characters, which makes possible a reflection about a society based on different socializations for men and women.
\end{abstract}

Keywords: The Handmaid's Tale. Patriarchalism. Margaret Atwood.

Beatriz Molari

Doutoranda no Programa de Pós-Graduação em Sociologia

Universidade Estadual de Londrina (UEL). E-mail: beatriz.molari@gmail.com 


\section{Introdução}

Publicado em 1985, o livro O Conto da Aia (título original The Handmaid's Tale), romance distópico da autora Margaret Atwood, retrata a vida das mulheres em uma teonomia ${ }^{1}$ totalitária e fundamentalmente cristã que derrubou o governo dos Estados Unidos. Com o sucesso da recente adaptação da obra para uma série de televisão e o crescente debate sobre a situação dos direitos das mulheres, a obra propicia uma discussão sobre o avanço do totalitarismo e seus reflexos no que tange à situação da mulher atual.

Abordando a retirada dos direitos civis conquistados pelas mulheres, o fanatismo religioso e a imposição de um regime de governo totalitário, O Conto da Aia retrata um mundo distópico no qual a mulher é colocada em uma situação de dominação baseada em preceitos patriarcais. Diante disto e com base em Simone de Beauvoir, Michelle Perrot, Maria Luísa Ribeiro Ferreira, Vera Soares, Flávia Biroli, entre outras, este artigo se propõe a discutir o patriarcalismo na obra de Atwood sob uma perspectiva sociológica.

\section{As mulheres no patriarcalismo: os não-sujeitos}

Em sociedades patriarcais, os indivíduos são concebidos pela socialização que lhes é imposta pelo sexo e gênero. Os termos "mulher" e "homem" recebem uma série de conceitos transmitidos pela vivência deste papel social. No patriarcalismo a mulher é definida como oposição ao homem. Este representa a totalidade, o centro das atividades de uma sociedade; enquanto a mulher é compreendida como "o outro", termo cunhado por Simone de Beauvoir em sua obra O Segundo Sexo, publicada originalmente em 1949. Para a autora, a relação mantida entre homens e mulheres tem como base a submissão e dominação. Beauvoir afirma que, pela categoria de gênero, a mulher não é determinada por ela mesma, mas pelo olhar do homem (BEAUVOIR, 2016). Para ela, "a humanidade é masculina e o homem define a mulher não em si, mas relativamente a ele; ela não é considerada um ser autônomo” (BEAUVOIR, 2016: 12). A realidade, sendo percebida pelo olhar do homem, mostra a mulher como a sua oposição, afirmando-se como essencial e colocando-a (“o outro”) como inessencial, o objeto (BEAUVOIR, 2016). Segundo a autora, quando a mulher é considerada "o outro" absoluto, o inessencial, torna-se impossível vê-la como um sujeito, sendo a sua existência medida em conformidade com a masculina, fazendo com que a relação entre estes dois grupos nunca seja autônoma e direta (BEAUVOIR, 2016).

1 Tem origem nas palavras gregas theos, que significa "Deus" e nomos, "lei". Portanto, "lei de Deus". Esta concepção possui relação com o Antigo Testamento, o qual aborda uma "lei do Senhor" (EINWECHTER, 1995). No livro, é apresentada como uma forma de governo que segue princípios e leis contidas no Antigo Testamento.

Texto de Beatriz Molari ( beatriz.molari@gmail.com ) 
Nas relações instauradas na dualidade do "outro", há a existência do princípio da reciprocidade. Para os brasileiros, o "o outro" são os italianos; enquanto para estes "o outro" são os brasileiros; para os proletários "o outro" é a burguesia; enquanto para esta o "outro" são os proletários. Contudo, na divisão por sexo não existe esta reciprocidade. Os homens definindo-se como "o essencial" negam a relatividade do outro grupo (as mulheres) e se estabeleceram como única alteridade. "A mulher aparece como o negativo, de modo que, toda determinação lhe é imputada como limitação, sem reciprocidade" (RIBEIRO, 2016). Baseada nesta colocação, a mulher em uma sociedade patriarcal quase sempre terá a sua existência pautada na submissão.

A compreensão da mulher como "o outro" promove uma série de construções sociais relacionadas ao seu desenvolvimento em sociedade. Concebida como a negação, o patriarcalismo atribuiu todas as oposições à mulher. $\mathrm{O}$ homem reconhecido como o símbolo da força, equilíbrio psicológico, liberdade sexual; a mulher a negação, frágil, histérica e com o dever de permanecer recatada. Isto é abordado por Maria Luísa Ribeiro Ferreira ao dizer que

\footnotetext{
Na aparente neutralidade do binômio masculino feminino, fruto da observação dos fenômenos da vida, paulatinamente se foram estabelecendo valorações, afirmando-se um elemento forte e um elemento fraco, um pólo que domina e outro que obedece, algo que representa a norma e algo que personifica a divergência. A hierarquia instala-se pois um dos pares categoriais coloca-se como modelo a seguir enquanto o outro é visto como negação ou falha (FERREIRA, 2007: 139).
}

O ato de colocar a mulher como "o outro", como destaca a autora, reforça uma relação de dominação. Se o homem é visto como a totalidade, a mulher será compreendia como a "incompleta", a epítome da submissão. Pensada por homens e para homens, a teoria do masculino como totalidade debruçava-se sobre a forma que a filosofia compreendia a mulher. Para Ferreira, “conceber a mulher como 'o outro' não é necessariamente uma teoria ética e politicamente incorreta. Só o é quando se reveste de uma conotação pejorativa em que o outro tende a ser secundarizado, ou discriminado ou simplesmente anulado" (FERREIRA, 2007: 139-140), como é o caso da atribuição da mulher como "o outro" numa sociedade patriarcal.

A identificação da mulher como "o outro" possui origem na dicotomia feminino/ masculino, debate já presente em BEAUVOIR, Ferreira explica que as dicotomias envolvem uma hierarquia valorativa que compreende o binômio dentro de uma relação de oposição e comando (FERREIRA, 2007), assim adentrando a submissão de um polo. $\mathrm{O}$ argumento para a diferenciação dos indivíduos se encontra na biologia, enfatizando a diferença entre os órgãos reprodutores. Contudo, como destaca Ferreira, a oposição homem/mulher se justifica no biológico, porém a diferença entre masculino/feminino possui valor cultural, relacionada com o imaginário social, uma ideologia e com as representações que caracterizam o que compõem um 
homem e uma mulher (FERREIRA, 2007). Esta construção social das características dos indivíduos dentro da dicotomia feminino/masculino é a definição de gênero. Assim como a autora, outros teóricos da defendem essa origem social do gênero. Segundo Michelle Perrot, o gênero não se encontra no sexo biológico e é aplicado designando as relações dos indivíduos pela cultura e pela história (PERROT, 2009). Então a dicotomia é resultado de um processo cultural, que diferencia os indivíduos e os impõe uma classificação dicotômica pautada no corpo. Dentro deste mesmo entendimento, Vera Soares afirma que "o termo gênero se refere à construção social da identidade sexual, construção que designa às pessoas diferentes papéis, direitos e oportunidades, de acordo com seu sexo; enquanto o sexo se refere às diferenças biológicas entre homens e mulheres" (SOARES, 2004: 113). O corpo é usado como argumento para a construção do gênero, mas este não se constrói nele. Beauvoir refuta o argumento biológico afirmando que "não é um corpo, é enquanto corpos submetidos a tabus, a leis, que o sujeito toma consciência de si mesmo e se realiza: é em nome de certos valores que ele se valoriza. E, diga-se mais uma vez, não é a fisiologia que pode criar valores" (BEAUVOIR, 2016:64). Tais conceitos são construídos socialmente, o que evidencia a construção social da representação do homem e da mulher, sendo esta em uma sociedade patriarcal, pautada na sua classificação como “o outro", a negação.

A classificação de gênero usa princípios culturais para moldar socializações diferentes para aqueles classificados como homens e as classificadas como mulheres. Para Soares, "as diferenças de gênero são constituídas hierarquicamente: a construção social do ser homem tem um maior status que a construção social do ser mulher" (SOARES, 2004: 113). É assim que uma sociedade patriarcal condiciona a atuação das mulheres, promovendo uma hierarquia que restringe suas possibilidades de atuação e as submetem às mesmas posições sociais (BIROLI, 2013). Situando a argumentação no corpo da mulher, o patriarcalismo usa a biologia para basear a relação de oposição homem/mulher. Sobre isto, Beauvoir afirma que

A sujeição da mulher à espécie, os limites de suas capacidades individuais são fatos de extrema importância; o corpo da mulher é um dos elementos essenciais da situação que ela ocupa neste mundo. Mas não é ele tampouco que basta para a definir. Ele só tem realidade vivida enquanto assumido pela consciência através das ações e no seio de uma sociedade; a biologia não basta para fornecer uma resposta à pergunta que nos preocupa: por que a mulher é o Outro? Trata-se de saber como a natureza foi nela revista através da história; trata-se de saber o que a humanidade fez da fêmea humana (BEAUVOIR, 2016: 65; grifo da autora).

Como a autora destaca, o corpo da mulher é usado como argumento para a definição da sua posição social, contudo, não é ele que a define, ou seja, não explica a colocação da mulher como "o outro". A autora ressalta ainda o papel da sociedade 
na determinação das posições sociais dos indivíduos. Assim sendo, o argumento biológico não corrobora a definição da mulher como oposição, mas reforça que a dicotomia homem/mulher surgiu pelo condicionamento dado às mulheres em uma sociedade patriarcal.

Origem da visão que coloca a mulher como "o outro", o sistema social patriarcal é reconhecido como "o regime da dominação-exploração das mulheres pelos homens" (SAFFIOTI, 2004: 44). Nesta estrutura, o homem é reconhecido como o poder primário e autoridade sobre os demais. Christine Delphy afirma que "nessa nova acepção feminista, o patriarcado designa uma formação social em que os homens detêm o poder, ou ainda, mais simplesmente, o poder é dos homens. Ele é, assim, quase sinônimo de 'dominação masculina' ou de opressão das mulheres” (DELPHY, 2009: 173). Dentro da relação de oposição propagada pelo patriarcado, a mulher é vista como um individuo submisso ao homem. Para que esta estrutura permaneça, são desenvolvidas estratégias de coerção social que reprimem o desenvolvimento da mulher. Assim, a dicotomia é mantida e, consequentemente, a dominação masculina.

\section{O Conto da Aia e o patriarcalismo}

Em O Conto da Aia a relação dicotômica homem/mulher é clara. O contexto retratado no livro aponta a ascensão de um governo teonomio e totalitário que chegou ao poder através de um golpe de estado que fechou o congresso dos Estados Unidos após o assassinato de todos os congressistas. Com o argumento da necessidade de estabelecer a ordem, a República de Gilead é instaurada e ocorrem mudanças estruturais. Não há imprensa ou universidades. Os opositores ao governo são fuzilados e seus corpos expostos em praça pública. O tratamento dado aos cidadãos é modificado. Em Gilead as mulheres não possuem direitos. Elas são divididas de acordo com a função que desempenham: há as esposas (ricas e exercem o símbolo de status ao lado dos maridos, os chamados comandantes), as marthas (responsáveis pelos afazeres domésticos), as tias (doutrinadoras, treinam as mulheres férteis em aias), as aias (utilizam o seu útero para a gestação dos filhos dos comandantes, desempenham somente a função de reprodutoras), as econoesposas (mulheres pobres que exercem todas as funções) e as não-mulheres (aquelas que rejeitam a doutrinação ou não servem para nenhuma das funções). Estas últimas são enviadas para as colônias, locais contaminados por radiação para executarem trabalhos braçais até a morte.

A protagonista é Offred, uma aia, posse do governo e que exerce unicamente a função de procriar. Antes da imposição de Gilead, Offred era chamada por outro nome, era casada e possuía uma filha qual foi tomada pelo governo e colocada para adoção. O governo de Gilead anulou todos os segundos casamentos, [e, no caso de] o caso de Offred, proibiu que as mulheres trabalhassem e confiscou todo o dinheiro das contas bancárias das mesmas. Sem direitos e recursos financeiros, as mulheres de Gilead foram coagidas pela nova estrutura que determinou seus papéis sociais. 
O patriarcalismo em Gilead fica evidente quando mencionadas as duas frentes usadas pelo governo para a imposição da submissão às mulheres: a anulação dos direitos civis e o confisco das fontes de independência financeira. Em uma sociedade patriarcal, as mulheres não são vistas como indivíduos, portanto não detêm os mesmos direitos civis que os homens. $\mathrm{O}$ ataque à independência financeira completou a violência de gênero retirando das mulheres qualquer possibilidade de resistência à nova estrutura social e evitou possíveis fugas para outros países.

As mulheres de Gilead tornaram-se posses dos homens, uma clara aplicação do patriarcalismo. A origem do termo patriarcado está na junção das palavras gregas "pater" e "arkhõ", que significam, respectivamente, "pai” e "eu governo", assim, o patriarcalismo é entendido como a autoridade paterna (masculina) sobre suas posses. O sentido da palavra "pai" não é restrito a descendência, mas demonstra toda a autoridade masculina sobre os membros da família e suas posses, portanto, uma concepção de dominação masculina (DELPHY, 2009). [Uma das] As primeiras ações do governo de Gilead foram [foi] instituir essa noção patriarcal de volta. Os homens foram designados como as autoridades dentro da nova estrutura, enquanto as mulheres tornaram-se posses, sendo do governo ou dos comandantes. Erika Apfelbaum ressalta que tal atitude é a primazia da dominação, pois, segundo a autora,

\section{4}

Toda relação de dominação, entre dois grupos ou duas classes de indivíduos, impõe limites, sujeição àquele(a) que se submete. Ela introduz uma dissimetria estrutural que é, simultaneamente, o efeito e o alicerce da dominação: um se apresenta como representante da totalidade e o único depositário de valores e normas sociais impostas como universais (APFELBAUM, 2009: 76-8o).

A dominação masculina é constantemente reforçada em Gilead. Vistos como totalidade, característica ressaltada por Apfelbaum no trecho anterior, os comandantes são representados como donos de tudo, inclusive das aias. O nome "Offred" não é o definitivo nome da protagonista, quer dizer "of Fred", traduzindo para o português, "de Fred”. Portanto, sugere uma posse, menção ao posto ocupado na estrutura social de Gilead. Ela não será sempre Offred, mudando de casa, muda-se o nome pelo qual é chamada.

As suas vestes também são um símbolo da sua função social, demonstrado no trecho a seguir:

Eu me levanto da cadeira, avanço meus pés para a luz do sol, em seus sapatos vermelhos, sem salto para poupar a coluna e não para dançar. As luvas vermelhas estão sobre a cama. Pego-as, enfio-as em minhas mãos, dedo por dedo. Tudo, exceto a touca de grandes abas ao redor de minha cabeça, é vermelho: da cor do sangue, que nos define. A saia desce à altura de meus tornozelos, rodada, franzida e presa a um corpete de peitilho liso que se estende sobre 
os seios, as mangas são bem largas e franzidas. As toucas brancas também seguem o modelo padronizado; são destinadas a nos impedir de ver e também de sermos vistas (ATWOOD, 2017: 16).

Assim como o nome, as roupas são empregadas como um lembrete da função social da aia para os outros, mas principalmente para ela mesma. "À nossa frente, à direita, fica a loja onde mandamos fazer vestidos. Algumas pessoas chamam-nos de hábitos, uma boa palavra para eles. Hábitos são difíceis de abandonar ou despir" (ATWOOD, 2017: 36). Esta afirmação identifica a intenção de tornar o hábito, veste, em um símbolo de uma função social e esta em um habitus, conceito desenvolvido por Pierre Boudieu. Segundo o autor, "o habitus, como indica a palavra, é um conhecimento adquirido e também um haver, um capital (de um sujeito transcendental na tradição idealista) o habitus, a hexis, indica a disposição incorporada, quase postural -, mas sim o de um agente em ação" (BOURDIEU, 2007: 61, grifos do autor). Podem ser definidos como um estado incorporado, o produto de uma aquisição histórica. Assim, o traje imposto às aias tem a proposta se de tornar um habitus de Gilead, ou seja, algo que será incorporado como um símbolo histórico ao ponto de não ser mais reconhecida a sua imposição. Tem-se, então, a naturalização do habitus, deste símbolo de dominação. Em um contexto de disputas entre dominador e dominado, a existência de uma instituição (nesse caso, podemos dizer Gilead), está no campo das forças complementares, como os habitus dos indivíduos que a define e redefine no social (BOURDIEU, 2007). Portanto, o nome e as vestes de Offread a lembram que ela não é mais um indivíduo, tornando-a um não-sujeito.

As aias são reduzidas a função social que ocupam. Muitas mulheres se tornaram inférteis em Gilead, o que é explicado no livro que seria em decorrência da contaminação por radioatividade usada pelo Governo. As poucas mulheres férteis tornaram-se aias, distribuídas pelas casas dos comandantes para gerar seus filhos. Esta função social é uma forma de objetificar as mulheres, reduzindo-as ao seu corpo, precisamente, ao seu útero. A dominação de Gilead é centrada na posse do corpo da mulher, impedindo-a de se reconhecer como um indivíduo, tal era anteriormente.

Minha nudez já é estranha para mim. Meu corpo parece fora de época. Será que realmente usei trajes de banho, na praia? Usei, sem pensar, entre homens, sem me importar que minhas pernas, meus braços, minhas coxas e costas estivessem à mostra, pudessem ser vistas. Vergonhoso, impudico. Evito olhar para baixo, para meu corpo, não tanto porque seja vergonhoso ou impudico mas porque não quero vê-lo. Não quero olhar para alguma coisa que me determine tão completamente (ATWOOD, 2017: 78).

Assim como as vestes e o novo nome, o corpo das aias foi transformado em um símbolo da dominação de Gilead. Offred não concebe o seu corpo como parte de si, mas como parte de Gilead e da função social para qual ela foi designada. A nova 
estrutura de Gilead reconstrói a concepção que as próprias mulheres têm de si e a que os outros indivíduos formam sobre elas, como fica evidente neste trecho: "Eu me acalmo e me componho. Aquilo a que chamo de mim mesma é uma coisa que agora tenho que compor, como se compõe um discurso. O que tenho de apresentar é uma coisa feita, não algo nascido" (ATWOOD, 2017: 82). Este trecho expõe a violência da dominação imposta por Gilead. O trecho a seguir destaca essa nova concepção do corpo para Offred:

Eu costumava pensar em meu corpo como um instrumento de prazer, ou um meio de transporte, ou um implemento para a realização de minha vontade. Eu podia usá-lo para correr, para apertar botões, deste ou daquele tipo, fazer coisas acontecerem. Havia limites, mas meu corpo era, apesar disso, flexível, único, sólido, parte de mim (ATWOOD, 2017: 90).

Carme Alemany explica que as violências praticadas contra as mulheres englobam atos que usam da ameaça, coação ou força para agredi-las na sua esfera pública e privada (no caso de Gilead, não há uma divisão destas), impondo-lhes sofrimentos físicos, sexuais e/ou psicológicos com o intuito de intimidá-las, ou seja, manter a sua submissão (ALEMANY, 2009). Nota-se que a dominação em O Conto da Aia se enquadra nesta definição. O controle sobre o corpo das mulheres evidencia uma violência física que se estende para o psicológico quando as mulheres já não concebem o seu corpo como parte de si. Seu corpo já não serve para expressar suas vontades, mas para cumprir uma função imposta. O corpo da aia já não é parte do indivíduo, mas uma posse compartilhada pelo Governo com os membros de alta posição de Gilead. Sem o controle mínimo sobre o seu próprio corpo, a concepção de não-sujeito se evidencia nessa distopia.

Assim como ocorre em uma sociedade patriarcal, em Gilead as ações do governo buscavam tornar a submissão feminina como algo natural. Bourdieu explica que a lógica da dominação é exercida em nome de um princípio simbólico que se mantém através do conhecimento e reconhecimento do dominador e do dominado de algo que os diferencia (BOURDIEU, 2012). No caso de O Conto da Aia, o sexo biológico e o que nele se origina socialmente, o gênero. Para o autor, as aparências biológicas são resultado de um trabalho de socialização do biológico, no caso o sexo, que produz nos corpos e nas mentes uma construção social naturalizada, o que, segundo Bourdieu, trata os gêneros como habitus sexuados (BOURDIEU, 2012). Então, se entende que o gênero é uma socialização que determina papéis sociais diferentes para os homens e para as mulheres com base em seu sexo biológico, tal qual é mostrado na obra de Atwood. Neste contexto, a dominação torna-se plena quando os dominados aplicam os esquemas produzidos pela dominação, ou seja, "quando seus pensamentos e suas percepções estão estruturados de conformidade com as estruturas mesmas da relação da dominação que lhes é imposta, seus atos de conhecimento são, inevitavelmente, atos de reconhecimento, de submissão" (BOURDIEU, 2012: 22, grifos do autor). Tal 
situação é almejada pelos detentores do poder em Gilead, como mostra o trecho reproduzido abaixo:

Vocês são de uma geração de transição, disse tia Lydia. É muito mais difícil para vocês. Sabemos os sacrifícios que são esperados de vocês. É duro quando homens as insultam. Para as que vierem depois de vocês, será mais fácil. Elas aceitarão seus deveres de boa vontade com o acordo de seus corações. Ela não disse: Porque elas não terão lembranças de nenhuma outra maneira. Ela disse: Porque não quererão coisas que não podem ter (ATWOOD, 2017: 143-144).

No referido excerto, a personagem tia Lydia, uma das mulheres responsáveis pelos centros de treinamento para as aias, expõe a reconhecimento da submissão mencionado por Bourdieu. A submissão feminina não seria mais contestada porque as mulheres não conheceriam outra forma de vivência. Não haveria mais fugas ou oposição à estrutura de Gilead, mas a passividade das mulheres dentro de uma sociedade feita por e para homens. Bourdieu explica que a estrutura social dentro da dominação masculina é feita do ponto de vista dos dominantes, fazendo-as ser compreendidas como naturais (BOURDIEU, 2012). O dominador sempre procurará associar negativamente tudo o que caracteriza o dominado. No caso do patriarcalismo, isto pode provocar uma autodepreciação ou autodesprezo sistemáticos que resultam em uma visão negativa das características das mulheres (BOURDIEU, 2012), inclusive pelas mesmas. Isto provoca uma valoração da dominação, levando ao entendimento de que as mulheres não podem possuir os mesmos direitos que os homens por serem tão diferentes do que a sociedade compreende por totalidade. Assim, mais uma vez, há o reconhecimento da submissão.

As ações descritas no livro foram impostas em Gilead por um motivo, o qual é revelado nas partes finais do livro. Ocorre em um diálogo entre Offred e o seu Comandante, quando o mesmo tenta justificar o movimento que levou à criação de Gilead. O trecho é reproduzido a seguir:

O problema não era só com as mulheres, diz ele. O problema principal era com os homens. Não havia mais nada para eles.

Nada?, pergunto. Mas eles tinham...

Não havia nada para fazerem, diz ele.

Eles podiam ganhar dinheiro, digo, um tanto maldosamente.

Não é o bastante, diz ele. É abstrato demais. Quero dizer que não havia nada para eles fazerem com as mulheres.

Como assim, que está querendo dizer?, pergunto.

Não estou falando a respeito de sexo, diz ele. Aquilo era parte do problema, o sexo era fácil demais. Qualquer um podia apenas comprá-lo. Não havia nada por que trabalhar, nada por que lutar. Temos as estatísticas daquela época. Você sabe a respeito 
de que eles mais estavam se queixando? Incapacidade de sentir. Os homens estavam perdendo o interesse pelo sexo. Perdendo o interesse pelo casamento.

\{..] Pensamos que faríamos um mundo melhor.

Melhor?, digo, em voz baixa, apagada. Como ele pode pensar que isto é melhor?

Melhor nunca significa melhor para todo mundo, diz ele. Sempre significa pior, para alguns (ATWOOD, 2017: 249-251).

Como o trecho retrata, os homens consideraram apenas a sua situação para propor uma mudança nas estruturais sociais. É evidente que tal prática não surgiu do nada, mas sim de uma cultura patriarcal enraizada naquela sociedade. Pode-se dizer, então, que Gilead representa o sistema patriarcalista em sua plena manifestação. Bourdieu explica que o pleno exercício da dominação masculina ocorre quando os homens são concebidos como prioridade nas estruturas sociais que, baseandose na divisão sexual do trabalho e de reprodução biológica e social, confere ao homem a melhor parte, assim mantendo esquemas de habitus que funcionam como matrizes de percepções, pensamentos e das ações de todos os membros da sociedade (BOURDIEU, 2012). O trecho da obra de Atwood condiz com a fala de Bourdieu. O sexo biológico e sua manifestação concreta, o corpo, foram usados como argumentos para uma nova estrutura social centrada em algo concebido como bem estar para os homens dentro de uma cultura patriarcal. Nota-se que a dominação é sempre reforçada e as funções sociais pensadas em um sistema de servidão que cabe a uma mulher desempenhar: serviços sexuais (aias), domésticos (marthas) e para exibição de um status civil (esposas). Para aquela que não serve para os propósitos de Gilead ou se recusa a ser passiva, o patriarcalismo indica outro destino: ser considerada uma não-mulher.

\section{Considerações finais}

A dominação masculina e o patriarcalismo são conceitos que possuem núcleos similares: ambos se sustentam na submissão das mulheres. O Conto da Aia retrata a aplicação de um sistema patriarcal centrado na concepção da mulher como um nãosujeito, uma posse do governo para servir aos homens.

Símbolos patriarcais estão presentes em toda obra. As vestimentas que determinam a função social de cada mulher, os códigos de conduta e, no caso das aias, a imposição de um novo nome. A estrutura social de Gilead foi construída centrando todas as atividades nos Comandantes, os reconhecidos como detentores de poder.

Tal como no patriarcalismo, em a obra de Atwood retrata uma sociedade na qual as mulheres não possuem voz, direitos e uma identidade. Não são vistas como indivíduos, nem mesmo as esposas, aquelas que ocupam o mais alto cargo que pode ser ocupado por uma mulher em Gilead. Estas são reduzidas à exibição de status, 
uma posição de servidão. As marthas representam a manifestação da domesticidade defendida pelo patriarcalismo, qual prega que é uma função da mulher cuidar dos serviços domésticos. As aias, por sua vez, representam a submissão e a plena caracterização de um não-indivíduo: não são donas sequer do próprio corpo. Sobre as não-mulheres, a situação destas é apresentada como uma ameaça constante para as outras categorias de mulheres. Caso alguma desagrade o seu comandante, será mandada para as colônias. O próprio nome sugere um domínio patriarcal, sendo aquelas que o governo não considera como mulheres, ou seja, aquelas que não possuem as características necessárias para viverem em Gilead. Isto evidencia que em $O$ Conto da Aia as mulheres não são concebidas como indivíduos, mas como objetos que são considerados "úteis" ou não pelo Governo.

A reflexão de $O$ Conto da Aia por meio de discussões sociológicas possibilita a compreensão da aplicação do patriarcalismo em uma sociedade. A obra tornou-se um sucesso mundial pelo avanço de discursos totalitários e misóginos em diversos países. Houve uma identificação das ações que, em 1985, foi escrito por Atwood em moldes de uma distopia, mas que podem ser visualizadas em sociedades centradas em socializações diferentes para homens e mulheres.

\section{Referências}

ALEMANY, Carme. (2009). Violências. In HIRATA, Helena. et al. (orgs.) Dicionário crítico do feminismo. São Paulo: Editora Unesp. p. 270-276.

APFELBAUM, Erika. (2009). Dominação. In HIRATA, Helena. et al. (orgs.) Dicionário crítico do feminismo. São Paulo: Editora Unesp. p. 76-80.

ATWOOD, Margaret. (2017). O conto da aia. Rio de Janeiro: Rocco.

BEAUVOIR, Simone de. (2016). O segundo sexo: fatos e mitos. 3 ed. Rio de Janeiro: Nova Fronteira.

BIROLI, Flávia. (2013). Autonomia e desigualdades de gênero: contribuição do feminismo para uma crítica democrática. Vinhedo: Editora Horizonte.

BOURDIEU, Pierre. (2007). O poder simbólico. 11 ed. Rio de Janeiro: Bertrand Brasil.

BOURDIEU, Pierre. (2012). A dominação masculina. 11 ed. Rio de Janeiro: Bertrand Brasil.

DELPHY, Christine. (2009). Patriarcado (teorias do). In: HIRATA, Helena. et al. (orgs.) Dicionário crítico do feminismo. São Paulo: Editora Unesp. p. 173-178. 
EINWECHTER, WILLIAM O. (2009). Ética E a Lei de Deus: uma introdução à teonomia. Brasília: Editora Monergismo.

FERREIRA, Maria Luísa Ribeiro. (2007). A mulher como "o outro": a filosofia e a identidade feminina. Revista da Faculdade de Letras: Filosofia, Porto, v. 23-24, n. 2. Disponível em: < https://ler.letras.up.pt/uploads/ficheiros/5612.pdf >. Acesso em: 18 jun. 2019 .

PERROT, Michelle. (2009). História (sexuação da). In: HIRATA, Helena. et al. (orgs.) Dicionário crítico do feminismo. São Paulo: Editora Unesp. p. 111-116.

RIBEIRO, Djamila. (2016). A categoria do Outro: o olhar de Beauvoir e Grada Kilomba sobre ser mulher. Disponível em: < https://blogdaboitempo.com.br/2016/o4/o7/ categoria-do-outro-o-olhar-de-beauvoir-e-grada-kilomba-sobre-ser-mulher/ > Acesso em: 14 dez. 2018.

SAFFIOTI, Heleieth Iara Bongiovani. (2014). Gênero, patriarcado, violência. São Paulo: Editora Fundação Perseu Abramo.

SOARES, Vera. (2004). Políticas públicas para igualdade: papel do Estado e diretrizes. In: T. Godinho \& M. L. da Silveira (org.), Políticas públicas e igualdade de gênero, São Paulo: Coordenadoria Especial da Mulher, (Cadernos da Coordenadoria Especial da Mulher). Disponível em: <https://library.fes.de/pdf-files/bueros/brasilien/o563o. pdf> Acesso em: 29 abr. 2019. 